Ästhetische Dermatologie

Dr. med. Tatjana Pavicic
Klinik und Poliklinik für Dermatologie und
Allergologie der LMU München
Koautoren: Dr. med. Gerd G. Gauglitz,
Prof. Dr. med. T. Ruzicka, München

51- Faltenbehandlung mit moderner Weichteilaugmentation

55- Überschießende Narben: neue präventive und therapeutische Ansätze

\title{
Geglättete Falten und unauffällige Narben
}

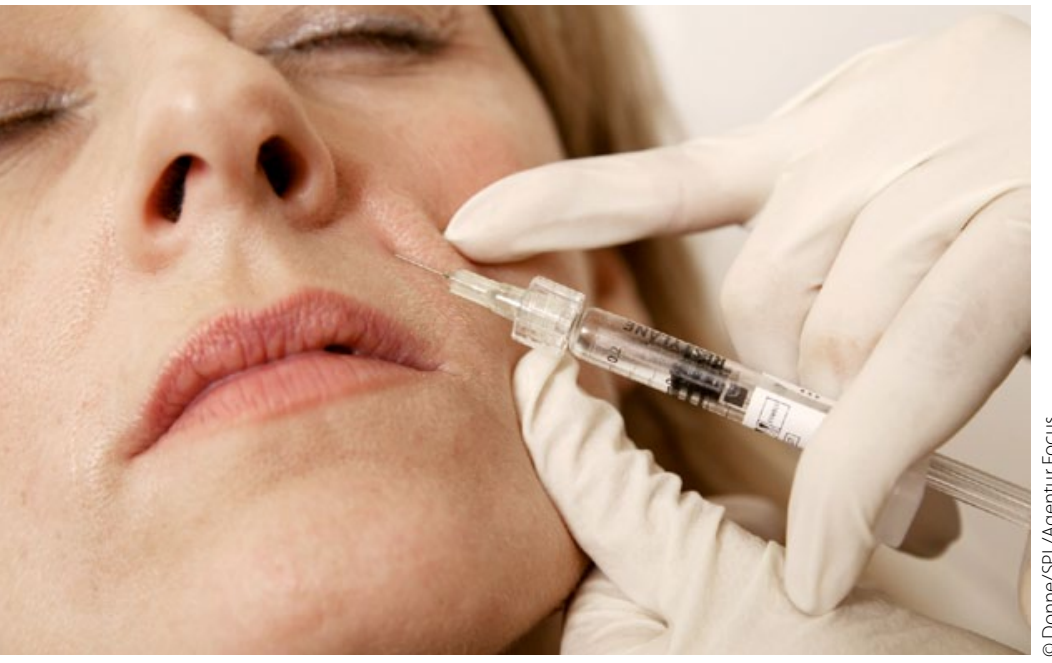

- Sonne, Umwelt, Lebensgewohnheiten und Krankheiten hinterlassen im Laufe des Lebens Spuren auf der Haut. Diese äußern sich u.a. in Form von Pigmentstörungen, Fältchen und Falten, Elastizitäts- und Konturverlust. Während das jugendliche Gesicht durch weiche, runde Züge ausgezeichnet ist und dreidimensional imponiert, erscheint das gealterte Gesicht insbesondere durch Volumenund Elastizitätsverlust eher zweidimensional. So alt wie die Menschheit selbst ist der Traum, die Erscheinungen des Älterwerdens zu mildern oder gar zu verhindern.

Der Einsatz von Füllsubstanzen hat zu einer enormen Erweiterung und Verbesserung der nicht chirurgischen ästhetischen Behandlungsmöglichkeiten beigetragen. Allein oder in Kombination mit anderen Behandlungen wie Laser-Resurfacing oder Botulinumtoxin A stellen sie eine sehr effektive und im Vergleich zu den konventionellen invasiven Verfahren auch eine kostengünstigere und schonende Anti-Aging-Methode dar.

Die Vorstellung, dass die altersbedingten Gesichtsveränderungen, insbesondere das „Absacken“ der Haut und der Verlust der jugend- lichen V- oder herzförmigen Gesichtsform, eine Folge der Atrophie des subkutanen Fettgewebes und des Umbaus knöcherner Strukturen sowie der Auswirkungen der Schwerkraft sind, legte den Grundstein für die Entwicklung eines neuen Behandlungsprinzips der Ästhetischen Gesichtsaugmentation. Demnach können die beschriebenen Alterserscheinungen größtenteils durch den Ersatz und die Redistribution des subkutanen Fettgewebes mit Hilfe von volumengebenden Fillern verbessert und die jugendliche Gesichtsform wiederhergestellt werden. Auf diesem Prinzip basiert auch der Paradigmenwechsel bzw. die neue Philosophie in der ästhetischen Weichteilaugmentation: „Weg vom Auffüllen einzelner Falten zur Rekonstruktion dreidimensionaler Gesichtsproportionen“. Die Unterspritzungen mit den Fillern, hier v.a. mit quervernetzten Hyaluronsäure-(HA-)Produkten, liegen mittlerweile auf Platz zwei aller ästhetischen Eingriffe weltweit.

Vor dem Hintergrund des zunehmenden Interesses an der Behandlung unschöner Narben sollen im 2. Schwerpunktbeitrag besonders die neueren Techniken zur Vorbeugung und Behandlung überschießender Narben vorgestellt werden. Nachdem Narben früher als Ausdruck von Heldenhaftigkeit oder Kampfgeist galten und ihre Träger eher "schmückten“, widersprechen auffällige Narben heutzutage unserem ästhetischen Empfinden. Der Wunsch, Operationen und Verletzungen ",narbenfrei“ zu überstehen, ist dementsprechend groß. In den letzten Jahren wurde das Spektrum etablierter Verfahren zur Behandlung überschießender Narben, wie beispielsweise Kryotherapie, intraläsionale Steroide, Druckverbände und operative Ansätze, durch die Einführung neuerer Techniken wie Laser, Imiquimod und intraläsional appliziertes 5-Fluorouracil erweitert. Für den bestmöglichen Therapieerfolg werden verschiedene Verfahren heute zunehmend miteinander kombiniert.

Trotz wachsender Erfolge in der Behandlung überschießender Narben bleibt die Prävention ungleich effektiver. Hier wird heute neben Druck, Silikonpräparaten und Zwiebelextrakt enthaltenden Narbengels auch die Anwendung von Botulinumtoxin A und Imiquimodcreme diskutiert. 